\title{
Interactive comment on "Towards thresholds of disaster management performance under demographic change: exploring functional relationships using agent-based modelling" by G. Dressler et al.
}

\section{Anonymous Referee \#2}

\section{Received and published: 1 August 2016}

The authors present an ABM work investigating the performance of disaster management organisations (DMO) under three incremental settings with coping time as the response variable. First, the number of DMOs is altered. Second, the capacity of DMOs, information access and number of disaster sites are additionally varied. A third analysis adds spatial heterogeneity. The authors find that the number of DMOs is the most important explaining variable. Capacity and information access are contributing to coping time to a lesser extend. Spatial heterogeneities are only showing a bigger effect under small lead times and partial knowledge. Rural areas are equated with a shrinking population which leads to reduction of DMOs. A main conclusion is that

Printer-friendly version Discussion paper 
performance is ensured in urban/downstream regions and at risk in rural/upstream regions. The work is a good example how stylized ABMs can deliver interesting insights and proves that we do not always need very complex, data driven ABMs to arrive there. The incremental approach of additional parameter variation in the three scenarios is convincing. I recommend the publication of the paper in Natural Hazards and Earth System Sciences although I have some minor remarks. I had some concerns with the (1) generality of statements with respect to the rural/urban duality and the (2) fuzziness of scenario descriptions. 1. The authors present two different geographic settings which should exhibit the same flood characteristics as the urban and the rural area are both lowland and downstream (Table 1). This approach makes sense in order to reduce the differences to road structures and spatial accessibility; to structures in space. However, the authors do not explicitly mention the ecological comparability in terms of lead time of the settings (which is btw necessary to have a meaningful comparison for a given lead time in figure 7). Moreover, they leave the reader with the impression that the spatial settings are "very different in the geographic location" p.10,I.14. (Table 1 relates the "geographic setting" to flood characteristics). P.7, I.15 also implies that you investigate "towns along the upper and lower reaches of the rivers". Moreover, table 3 presents "possible implications [..] of [..] geographic settings" which are based on argumentation and not on simulation results. E.g. is a rural downstream region at more risk compared to an urban upstream region? My point is that the authors should make it more clear what can be derived from the two presented geographical settings and what is derived from an argumentative standpoint. This general remark applies for the respective passages throughout the whole manuscript. 2 . While I find the iterative approach of scenario analysis convincing, I had problems to clearly relate the four subsections in the results part to them. E.g. figure 7 is used for the analysis of two scenarios. Would it not be a better approach to dissect your analysis into themed sections? Here, one could think about (1) social, (2) ecological and (3) spatial change. For (1): an analysis of \#DMOs, capacity and knowledge for a given lead time and \#disaster sites. For (2) you would add \#disaster sites (which you did in figure 6) and lead

Printer-friendly version

Discussion paper

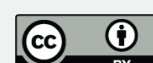


time. And for (3) you present figure 7 differentiating the upper variables by the two geographical settings. What I would suggest is a restructuring of the presentation of results. Table 2 is a good attempt for a themed presentation. However, why is the variation of lead time not part of the climate change process there? Is lead time not subject to climate change? Should there not be a correlation between flood intensity and lead time? Please discuss this relationship at least. Spatial heterogeneity is missing in the "Scenario overview" table as it only deals with processes. The latter is a good example for the fuzziness of the scenario description.

Minor remarks: 3. Abstract, last sentence. Either mention the implications or delete. Don't refer to a section in the abstract. 4. Introduction, p.1, I.24-30: Refer to relevant literature. 5. The intensity of events is reflected by the \#disaster sites and the \#sandbags needed. But how is the frequency of events reflected (p.6.I.23)? Is this part of the analysis or the argumentation? 6. Section 2.2: Can you explain why there can be a "discrepancy between coping capacity and demand"? Is coping capacity (which you measure as coping time) not a function of demand (+resources). I could understand if there is a discrepancy between resources (\#dmos) and demand (\#sites + \#sandbags needed) Maybe that would need reformulation. 7. P. 6, I. 17: the concept of resilience is suddenly appearing here. Please explain which definition of resilience you are referring to at this point. Hint: you are using an engineering resilience concept with resilience as return time (Maybe cite Rasch et al. 2016). Moreover, you use the concept of absorptive capacity (Maybe cite Bene et al. 2012). 8. P.7,. I. 27-28: Change has an effect on population growth/shrinkage? Isn't population growth/shrinkage itself the demographic change which is different wrt to the level of urbanisation? Please rewrite. 9. P.11, I.28: Can you give some examples for such heuristics? 10. P.12, I.9-10: The resilience concept is established in the context of disaster management. Please specify why the ses resilience concept is especially useful here (or skip sentence). 11. P.12, I.21: why was Dawnson (2011) not mentioned in the introduction?

References Béné et al. (2012): Resilience: New Utopia or New Tyranny? Reflection

Printer-friendly version

Discussion paper 
about the Potentials and Limits of the Concept of Resilience in Relation to Vulnerability Reduction Programmes, Institute for Development Studies, Working Paper 405

Rasch, S., Heckelei, T., Oomen, R. (2016): Reorganizing resource use in a communal livestock production socio-ecological system in South Africa. Land use policy 52: 221231.

Interactive comment on Nat. Hazards Earth Syst. Sci. Discuss., doi:10.5194/nhess-2016-48, 2016. 